\title{
ENTREVISTA COM O PROFESSOR RONALDO PARENTE: O ÁRDUO CAMINHO PARA PUBLICAÇÕES INTERNACIONAIS DE ALTO IMPACTO
}

\author{
Ronaldo Couto Parente \& * llan Avrichir \\ Escola Superior de Propaganda e Marketing - ESPM, São Paulo, (Brasil) \\ Florida International University, Miami, (Flórida)
}

\section{Por Professor Ilan Avrichir}

No mês de setembro, a InternexT entrevistou um dos brasileiros com maior destaque mundial no cenário de Estudos sobre Negócios Internacionais. A entrevista foi feita para poder compartilhar as reflexões do entrevistado, sobre o caminho a ser trilhado para publicar em periódicos de alto impacto. A entrevista foi conduzida pelo editor da Internext, llan Avrichir e editada com a colaboração de Silvio Luís de Vasconcellos ${ }^{\S}$.

O entrevistado é o professor Ronaldo Couto Parente, natural do Rio de Janeiro, engenheiro civil, formado na UNIFOR - Universidade de Fortaleza, tem Ph.D. em gestão estratégica em negócios

**. Publicar no JIBS é o sonho de qualquer pesquisador da área de negócios internacionais. $O$ que você pode dizer para pesquisadores que queiram publicar no JIBS?

Prof. Ronaldo Parente: Antes de mais nada, me permita fazer uma correção, que pode parecer um tanto arrogante, mas acredito que é importante no internacionais pela Temple University, nos Estados Unidos e mestrado em finanças pela Universidade de Tampa. Além de editor e revisor em periódicos de impacto na área de negócios internacionais e estratégia, possui publicações em todos os cinco principais periódicos especializados e $m$ sua linha, nos últimos dez anos. É professor titular da Florida International University, de Miami e professor colaborador na Fundação Getúlio Vargas, EBAPE, Rio de Janeiro.

Prof. Ilan Avrichir: Como editor da InternexT, gostaria de lhe agradecer por ter aceitado o convite em participar desta entrevista. $O$ que me motivou a pedir essa entrevista foi o fato de você ter acabado de publicar um artigo no JIBS

contexto da nossa entrevista. Esse meu artigo sobre catch-up ${ }^{\dagger+}$ e A Embrapa ${ }^{\ddagger \ddagger}$ que recentemente foi publicado no JIBS, em maio de 2020, é o meu quinto artigo nesse periódico. Um sexto encontrase em processo de revisão e deve ser sair em breve. Penso que esse adendo pode contribuir ainda mais em responder sua pergunta.

\section{* iavrichir@espm.br}

$\S$ Ilan e Silvio são professores do Programa de Pós Graduação em Administração da ESPM. Sílvio foi coorientado em sua tese pelo professor Ronaldo Parente. O processo de transformação da entrevista gravada em texto contou com a participação do doutorando Cláudio Bezerra de Mello, do mesmo programa.

** JIBS. Journal of International Business Studies. A revista científica com maior fator de impacto entre todas as do campo de negócios internacionais.

${ }^{++}$Catch-up tecnológico é um termo de difícil tradução para o português e por isso costuma ser usado em sua forma original. Trata-se do processo pelo qual o crescimento da produtividade, ao longo do tempo, é devido à incorporação de avanços tecnológicos e se reflete na acumulação de ganhos monetários ou de capital (Abramovitz, 1986; Parente et al., 2020).

¥¥ O artigo aqui citado (Parente et al., 2020) inicia com a provocação: Como pode uma economia emergente, assolada por desafios políticos, econômicos e de recursos, impulsionar o processo de atualização de tecnologia no setor agrícola e, então, forjar um ecossistema para facilitar a geração e disseminação contínuas de inovações? 
A primeira coisa que eu diria a quem quer publicar em um jornal top tier é fazer antes uma reflexão do porquê ele ou ela quer publicar no JIBS, por exemplo. Nas vezes em que publiquei, no JIBS, o tempo médio para escrever o artigo, submeter e concluir o processo de revisão foi em média três anos. Para certas carreiras, talvez não seja o caso de publicar no JIBS, uma vez que existem outros periódicos internacionais muito bons, que também são A1 no Estrato Qualis e que requerem bem menos esforço. Se o pesquisador não pretende fazer carreira internacional, talvez não seja o caso de ele enfrentar esse desafio. Publicar no JIBS ou em um outro periódico que tenha fator de impacto dois, mais ou menos, vale a mesma coisa em termos de pontuação na maior parte das universidades brasileiras, que se guiam pelo Estrato Qualis. Então, o incentivo para publicar no JIBS pode não estar claro para o pesquisador dependendo da carreira que pretende seguir. Ele ou ela precisam pensar se realmente está com disposição para fazer esse esforço adicional e no final ter o mesmo reconhecimento de um outro A1 com bem menos esforço.

Prof. Ilan Avrichir: Boa reflexão. Porém, vamos supor que o pesquisador ou pesquisadora concluiu que quer publicar no JIBS ou em outro periódico internacional com alto fator de impacto. $O$ que você recomendaria?

Prof. Ronaldo Parente: Se ele ou ela está decidido a isso, uma questão à qual precisa estar bem atento é a estrutura de artigo que os periódicos internacionais de primeira linha, em sua maioria, anglo-saxões, estão exigindo. Essa estrutura tem alguns pontos chave que, infelizmente, vários artigos de pesquisadores brasileiros ainda não obedecem. Um desses pontos é a revisão de literatura. Minha percepção é que, muitas vezes, o que se encontra no artigo é uma revisão bibliográfica e não uma revisão de literatura.

\footnotetext{
$\S \S$ Ronald Coase (1910-2013), prêmio Nobel de Economia, de 1991, desenvolveu seus estudos sobre a natureza da firma e as implicações do ambiente em que está inserida sobre as atividades que ela desenvolve. Duas de suas obras, A Natureza da Firma (1937), fruto de sua tese de doutorado, escrita quando tinha 27 anos, e O Problema do
}

Prof. Ilan Avrichir: E qual é a diferença entre as duas revisões e por que isso é tão importante?

Prof. Ronaldo Parente: Na revisão bibliográfica, você vai resgatando tudo que foi escrito sobre o assunto e dizendo o que já foi feito e quais foram as contribuições. Na medida em que o pesquisador vai lendo artigos, constrói um banco de dados, com os pontos mais importantes destacados na leitura. Se quiser usar depois, já está lá. Essa é uma técnica de construir uma revisão bibliográfica. No entanto, a revisão de literatura é diferente. A revisão de literatura começa com a questão de pesquisa que você quer responder. É preciso entender, dentro daquela questão de pesquisa, o que que foi feito recentemente, ou seja, aquilo que está sendo estudado nos periódicos de impacto semelhante àquele que é alvo da publicação. Quando faço uma revisão de literatura, procuro identificar quem são os dez pesquisadores (as) que estão discutindo aquele assunto no momento, para que eu possa fazer parte do debate e discussões que estão em andamento. Lembrando que para isso não se pode se limitar apenas aos artigos já publicados, mas precisa também ler "working papers" e participar ativamente as principais conferências sobre o tópico. Então, na revisão de literatura que vai no artigo, você vai citar um ou outro artigo clássico para dar um sabor, mostrando que você conhece a literatura dos clássicos assim como as teorias de base sobre o assunto. Por exemplo, vale citar o Coase ${ }^{\S \S}$, se a base é a Teoria da Firma ou o Williamson $^{* * *}$, se for Teoria dos Custos de Transação. Entretanto, o foco deve ser entender o estado da arte atual sobre o tópico o qual o pesquisador(a) está querendo oferecer sua contribuição incremental.

Prof. Ilan Avrichir: Quer dizer que o objetivo da revisão bibliográfica e o objetivo da revisão de literatura não são os mesmos?

Prof. Ronaldo Parente: Exatamente. A revisão bibliográfica precede a revisão de literatura e servirá de suporte para escrever a revisão de

Custo Social (1960) são basilares em diferentes perspectivas nas áreas de ciências sociais e humanas.

*** Oliver Williamson (1932-2020), prêmio Nobel da Economia, de 2009, avançou nos estudos de Coase sendo um dos pilares da Teoria dos Custos de Transação (1975). 
literatura, que e o que vai no paper final. Penso na revisão bibliográfica como um banco de dados de suporte ao pesquisador. Já a função da revisão de literatura é inserir-se na conversação que está acontecendo agora sobre o assunto em questão, para que você possa dar sentido ao gap que você está apontando, ou seja, é a base da lacuna teórica para a qual sua pesquisa vai contribuir. A revisão da literatura deve ser sucinta, não mais de quatro, cinco páginas, dirigida para situar a sua pesquisa na conversa que os autores protagonistas do campo estão tendo no momento. Não é o local em que você vai mostrar que conhece a história do campo; esse é um problema que eu vejo em muito dos artigos escritos por brasileiros, inclusive meus alunos.

Prof. Ilan Avrichir: Quer dizer, uma revisão da literatura recente dirigida para situar minha pesquisa na discussão corrente. O que mais? Se eu fizer isso, eu consigo publicar no JIBS?

Prof. Ronaldo Parente. Sem isso você não consegue publicar, mas não é só isso. Outra questão importante é a estrutura da introdução do artigo. A introdução deve dizer, logo no primeiro parágrafo, porque o tópico que estou estudando é interessante e relevante. Você tem que, já na introdução, prender a atenção do editor e dos revisores. Após a leitura da introdução, tanto o editor assim como os revisores têm que pensar: esse autor realmente entende do assunto $e$ comprovou que existe um gap que merece ser estudado a fundo. Se você não passar nesse teste, você logo é rejeitado e, infelizmente, é isso que acontece com muitos autores brasileiros que escrevem introduções muito longas em que essas questões não ficam claras.

Prof. Ilan Avrichir: Ótimo, revisão de literatura e introdução são fundamentais. Para o que mais você chamaria a atenção dos autores brasileiros?

Prof. Ronaldo Parente: Eu gostaria de comentar algo sobre artigos qualitativos. Os pesquisadores brasileiros ainda tendem a escrever muitos artigos

\footnotetext{
${ }^{++\dagger}$ Em 2019, juntamente com outro pesquisador brasileiro e um chinês (Parente et al., 2019), Ronaldo Parente publicou um artigo sobre como as empresas multinacionais sustentam operações em ambientes institucionais distintos e desconhecidos, estudando o caso de uma empresa multinacional estatal chinesa que iniciou
}

qualitativos. Na minha opinião, dizer que os editores não gostam de publicar artigos qualitativos não procede, é um mito. Você deve ter visto que meu último artigo no JIBS é qualitativo, assim como o artigo de $2019^{\text {t+ }}$. Para você publicar um estudo qualitativo há certos critérios que você precisa preencher.

Em geral, um bom estudo qualitativo trata de um fenômeno novo, uma coisa sobre a qual está muito difícil coletar dados. Algo que desperte interesse e que há uma percepção no meio acadêmico que não há dados para testar o fenômeno, quantitativamente. Essa é uma questão crítica: a escolha do fenômeno que você vai estudar. E, logicamente, o nível de detalhes que você é capaz de coletar. Em pesquisa qualitativa você não pode deixar de explicar em detalhes o que você fez, como coletou os dados, quanto tempo durou as entrevistas, que perguntas foram feitas. O nível de detalhe tem que ser quase como se você estivesse falando para uma criança de cinco anos de idade. Eu vejo muitos estudos qualitativos que pegam uma empresa e simplesmente contam a história dela. Uma pesquisa qualitativa não pode ser apenas uma ilustração do fenômeno ou da teoria que você está investigando. Infelizmente, eu vejo muita submissão de pesquisa qualitativa que é isso: "meu caso está de acordo com a teoria X". Isso não vai passar e ser publicado numa revista top ${ }^{\ddagger \neq \ddagger}$.

Prof. Ilan Avrichir: Em suma, vimos até aqui a revisão de literatura, a introdução e que, se o artigo for qualitativo, precisa abordar um assunto novo, que não tem abundância de dados sobre ele e com a metodologia e argumentação cuidadosamente descrita e sustentada.

Prof. Ronaldo Parente: Sim, eu acho que você fez uma boa síntese do que eu disse até aqui.

Prof. Ilan Avrichir: Na sua opinião, por que os pesquisadores brasileiros publicam pouco em periódicos como o JIBS?

e desenvolveu suas operações na República Democrática do Congo.

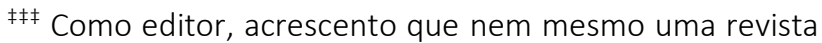
com menor fator de impacto se interessará somente pela história sem que haja algo novo a ser discutido. 
Prof. Ronaldo Parente: Bom, em primeiro lugar, porque é difícil para qualquer um. Porém, se eu comparo o Brasil com os Estados Unidos, uma coisa que me chama a atenção é como as aulas dos programas de doutorado são dadas aqui nos Estados Unidos e no Brasil. Aqui nos Estados Unidos, mesmo as cadeiras de formação teórica são dadas em formato de seminário. Eu, por exemplo, sou responsável pela disciplina de Global Strategy na FIU. Eu peço para os alunos lerem de seis a oito artigos por semana. Eles precisam ler esses artigos e preparar uma pequena revisão de literatura semanalmente. Na medida em que disciplina avança, a revisão de literatura tem que incluir os artigos das aulas anteriores também. Então, no final da disciplina, ele vai ter uma super revisão da literatura. Isso força o aluno a escrever uma revisão de literatura como ela deve ser. O processo é lento e gradual, mas não tem outro jeito de aprender a escrever uma boa revisão de literatura senão por tentativa e erro.

Prof. Ilan Avrichir: Isso é algo que você faz ou todos os professores fazem?

Prof. Ronaldo Parente: Me parece que é a norma. É como todos os professores lecionam, mesmo nas disciplinas de formação teórica, como Organization Theory, Organization Behavior ou International Business Theory. No segundo ano do curso, o aluno ou aluna, em geral, está fazendo três seminários, está lendo 18 a 24 artigos por semana sobre três tópicos diferentes. Portanto, vai aprender a escrever academicamente. Penso que isso é super importante e reflete a forma de ensinar um doutorando daqui nos Estados Unidos e no Brasil. Dar aula para doutorado é bem diferente do que para o mestrado. No doutorado, você precisa ensinar o aluno a escrever academicamente. É importantíssimo que o aluno de doutorado publique antes de terminar se quiser conseguir um bom emprego.

Prof. Ilan Avrichir: Para entender melhor esse contexto que contribui na formação de autores, vou fazer-Ihe algumas perguntas mais específicas sobre a maneira como se ensina e se aprende nos Estados Unidos. Por exemplo, como é seu estilo de dar aula?

Prof. Ronaldo Parente: Tipicamente, eu me sento com os alunos em volta de uma mesa e discutimos os textos e o que eles produziram na semana. É uma conversa, uma discussão. Não tem muitas apresentações.

Prof. Ilan Avrichir: Quantos alunos você costuma ter na sua disciplina de Global Strategy?

Prof. Ronaldo Parente: De três a sete, mas o normal é entre quatro e cinco alunos. As turmas de doutorado são sempre bem pequenas.

\section{Prof. Ilan Avrichir: E como é a orientação?}

Prof. Ronaldo Parente: A cada uma ou duas semanas o orientando me manda um resumo do que está fazendo. Eu leio, reviso e tenho uma reunião com ele de uma hora, uma hora e meia quando discutimos o que está fazendo, como está sua produtividade e ajustamos os próximos passos e atividades que devem ser feitas. Procuro sempre manter o orientando alerta e produzindo para não perder o ritmo. Quando tenho mais de um orientando ao mesmo tempo e identifico semelhanças nos interesses de pesquisa procuro incentivar a colaboração entre alunos para gerar publicações.

Prof. Ilan Avrichir: E quantos orientandos você tem, em média?

Prof. Ronaldo Parente: De um a dois de cada vez. Não dá para orientar muitos pois a orientação aqui nos EUA é muito intensa.

Prof. llan Avrichir: Como é o processo de seleção de sua universidade no doutorado?

Prof. Ronaldo Parente: O College of Business aceita dez novos alunos por ano, mas o departamento de International Business / Strategy, que é o meu, aceita apenas dois, por ano. Temos sempre 8 a 10 alunos simultaneamente uma vez que o tempo total para conclusão varia entre 4 e 5 anos.

Prof. Ilan Avrichir: E quantos professores atuam no programa?

Prof. Ronaldo Parente: Somos uns 25 a 30 no total no nosso departamento. Porém, professores de doutorado, que trabalham com orientação, somos uns oito ou nove.

Prof. Ilan Avrichir: E como é o processo de seleção? 
Prof. Ronaldo Parente: Nós damos o primeiro corte pelo GMAT ${ }^{\S \S \S}$. O mínimo para nós é 650 . Se não tiver 650 já é cortado. Em geral sobram em torno de 25 após esse corte inicial. Esses, vamos analisando, fazendo entrevistas, em suma, o comitê de seleção olha tudo. Porém, a palavra final é do professor. Ele tem que olhar toda a documentação do aluno e dizer que orientaria o candidato. Não adianta trazer um aluno novo se não houver um match entre os interesses de pesquisa do aluno e do professor.

Prof. Ilan Avrichir: Ronaldo, do que você falou, parece claro que as condições que o professor tem para lecionar e orientar e o nível de preparo e potencial do aluno de doutorado nos Estados Unidos é bem diferente do que existe na grande maioria, senão em todos os programas de doutoramento no Brasil. Portanto, é razoável supor que o nível de preparação e condições para um jovem doutorando ou mesmo para um doutor experiente no Brasil é bem diferente do que o nível de preparo de seu par americano. Dado isso, o que você diria a um jovem pesquisador brasileiro que quer publicar num periódico de alto impacto, que, usando suas palavras, é difícil mesmo para um pesquisador que se formou com todas essas condições e preparo?

Prof. Ronaldo Parente: A primeira coisa que eu diria é que é perfeitamente possível. Eu tenho visto um fluxo de pesquisadores brasileiros vindo para os Estados Unidos e isso não seria possível se eles não tivessem publicações excelentes. Também tenho visto várias publicações em periódicos excelentes de pesquisadores brasileiros, com e sem a coautoria de americanos e europeus. Mesmo assim, uma coisa que eu recomendaria aos brasileiros é que tentem publicar com autores de fora do Brasil.

\section{Prof. llan Avrichir: Como se consegue isso?}

Prof. Ronaldo Parente: Muitos pesquisadores brasileiros já sabem o que vou falar, mas não custa enfatizar. O melhor jeito é começar a aparecer em conferências internacionais. Nas conferências internacionais, o melhor jeito, se você for um pesquisador jovem ou recém formado, é participar dos consórcios doutorais ou dos consórcios de junior faculty. É nesses ambientes que a gente conhece, faz amizade e depois fica em contato. Por exemplo, eu sou amigo do Jay Barney ${ }^{* * *}$ e Mike Peng ${ }^{\text {t+t }}$ e mais vários outros pesquisadores que hoje são referência. Todos, conheci em junior faculties e consórcios doutorais.

Há outras formas de fazer relacionamentos internacionais nessas conferências. Eu recomendaria, vá nas reuniões dos grupos de interesse e se ofereça como voluntário para fazer trabalhos para as comunidades da área. Eles estão sempre precisando de gente para fazer algum trabalho. Vá nos encontros com os editores de periódicos e se ofereça para ser parecerista. Os editores estão sempre precisando de revisores. $\mathrm{E}$ aí, seja um revisor que entrega a coisa no prazo porque, normalmente, poucos entregam. Então, o editor começa a notar você. Não adianta só ficar mandando e-mail e pedindo favores; ele ou ela é muito ocupado e não vai lhe atender. Eu, por exemplo, recebo uns 300 pedidos como esses, por dia. Se possível, escolha conferências pequenas

mais de 75.000 citações no Google Acadêmico, em 2020, e de leitura obrigatória para entender como a visão baseada em recursos se tornou relevante ao atribuir às especificidades dos recursos da firma a razão para sua diferenciação no ambiente competitivo.

${ }^{++++}$Mike Peng é um dos autores mais citados quando se estuda estratégia com base nas instituições. Propôs a metáfora do tripé da estratégia (Peng \& Pinkham, 2009), usado com frequência em negócios internacionais para aliar as visões da indústria, dos recursos e das instituições para entender como as organizações desenvolvem suas estratégias em mercados internacionais.
** Jay Barney e um dos mais conhecidos autores na áre de estratégia. Entre seus artigos, Firm Resources and Sustained Competitive Advantage (Barney, 1991) possui
§§ GMAT é a abreviatura de Graduate Management Admission Test, teste de admissão para pós-graduação em o, MBA, mestrado e doutorado. É um ex raciocínio lógico, raciocínio quantitativo que anális interpretativa e raciocínio crítico, além de um ensaio de avaliação da escrita. A Universidade de Princeton oferece informações em seu website (Princeton, 2018). O GMAT pode alcançar até 800 pontos, porém, notas acima de 600

são consideradas altas.

Internext | São Paulo, v.16, n. 1, p. 12-18, jan./abr. 2021 
com clima acolhedor, como a AIB ${ }^{\ddagger \neq \neq \ddagger}$, AIB LAC ${ }^{\S \S \S ~ o u ~}$ EIBA $^{* * * * *}$. Os pesquisadores brasileiros são inteligentes e criativos, têm acesso a dados que interessam aos pesquisadores dos principais centros. Isso não vale apenas para os jovens pesquisadores. Fazer parcerias de pesquisa interessa aos dois lados. Em suma, há várias formas de um brasileiro buscar estabelecer essas parcerias, mas as conferências representam um dos canais mais favoráveis.

Prof. Ilan Avrichir: Nossa entrevista já está se alongando, mas antes de terminar eu gostaria de lhe fazer duas perguntas. A primeira é sobre uma crença que é muito partilhada entre pesquisadores brasileiros. A crença de que se você não escrever com um pesquisador famoso ou que esteja afiliado a uma universidade famosa, é muito difícil publicar num periódico de impacto. $O$ que você diria disso, verdade ou mentira?

Prof. Ronaldo Parente: Verdade e mentira. Mentira porque ninguém vai facilitar a aceitação do seu artigo na revista, nem vai passar porque lhe conhece ou mesmo passar seu trabalho na frente de outros. Porém, é também verdade porque isso aumenta sua chance de não ser rejeitado pelo editor antes de passar para revisão entre pares, o chamado Desk Reject. Você tem que lembrar que o editor está numa posição muito difícil, porque, para ele ou ela, arranjar um bom revisor é difícil. O revisor trabalha de graça, provavelmente é muito solicitado e poderia estar fazendo outra coisa. Então, o editor não pode abusar desse parceiro. Ele teme mandar uma coisa que não seja boa o suficiente e desperdiçar o tempo do revisor. Se ele não entender bem o seu artigo é provavelmente porque a sua contribuição não ficou clara na introdução e na revisão de literatura, então ele pode preferir não mandar para os pareceristas e Ihe tirar fora logo do processo com um Desk Reject. Entretanto, se o artigo vem de uma pessoa que ele sabe ser muito boa no assunto, com boa reputação na área, e com o bom currículo de publicação,

$\ddagger \ddagger \neq$ Academy of International Business. Possui conferências anuais em diferentes países do mundo, com diferentes linhas de pesquisa. Em 2021 deverá ocorrer em Miami.

$\S \S \S$ Capítulo latino-americano e caribenho do AIB. Desde 2020, passou a incluir o Caribe. Ocorre em diferentes países da região, em formato semelhante ao AIB. então isso pode fazer o editor dar um voto de confiança ao artigo e mandar para frente para entrar no processo de revisão, o chamado Blind Review.

Ressalto, porém, que achar que ter um coautor conhecido vai facilitar o processo de revisão, é bobagem. O processo de revisão é sério e você vai ter que convencer os revisores de que aquilo que você escreveu é relevante e bom. Não tem jeito. É lógico que você não precisa convencer a todos os revisores; se você convencer dois e um continuar contra, normalmente o editor vai ficar com a opinião dos dois que aprovaram. Você pode ganhar o jogo por 2 a 1, 3 a 1, não precisa ganhar de 4 a 0. Mas achar que alguém publica porque é conhecido, porque o editor é amigo, isso é bobagem. Eu tenho grandes amigos na academia que são editores; a gente toma cerveja juntos e eles já me rejeitaram três ou quatro vezes, cada.

Prof. llan Avrichir: Agora a última questão que eu gostaria de fazer. Eu gostaria de saber sua opinião sobre duas pesquisas de alunos meus. Estou justificando para mim mesmo esse pedido, mas penso que é de interesse para todos os leitores. Uma pesquisa é sobre a relação de governança entre o Estado e os contratados, em desastres ambientais. A outra pesquisa é inspirada muito no seu artigo sobre o catch-up tecnológico e a Embrapa, que saiu no JIBS. No caso, a produção de uma commodity agrícola que o Brasil importava, em menos de dez anos deixou de importar e o Brasil se tornou o segundo maior exportador global. Esse é o nosso caso, como é que acontece uma evolução como essa em apenas 10 anos.

Prof. Ronaldo Parente: Me parece, que esses dois casos são estudos de caso longitudinais. Isso é relevante porque você não tem dados disponíveis para provar. O primeiro ponto a observar é ter fundamentação teórica, alguma teoria por exemplo, no caso da governança, usar teorias de governança para tentar explicar as causas e efeitos que aconteceram ao longo da história. Peguem seis

\footnotetext{
***** European International Business Academy. De maneira semelhante ao AIB, também possui acoOlhe pesquisas de diferentes linhas. O único EIBA que ocorreu fora da Europa, foi no Brasil, em 2015, no Rio de Janeiro.
} 
anos e mostrem como o que aconteceu ao longo do período culminou no desastre. Examine como essas teorias poderiam explicar o que aconteceu. A contribuição é voltada para os desenvolvedores de políticas públicas, para não voltarem a cometer o mesmo erro. Isso é um caso excelente e deve ser abordado qualitativamente. Se for bem feito, pode ter sucesso. O outro caso, da commodity também pode ser excelente e é muito parecido com o meu paper sobre a Embrapa. Você vai ter que estudar bem a história e vai ter que identificar dois ou três períodos distintos. Em cada período, deve ser fácil de explicar com algumas características e relacionar isso com uma fundamentação teórica robusta. Depois, você deve promover a discussão se o que foi feito no Brasil com esta commodity pode ser replicado em outras culturas ou se pode ser replicado por outras empresas. Aí você tem um grande artigo. Os dois são candidatos muito bons para estudos qualitativos e vai ter vários periódicos que se interessarão por este tipo de artigo. Mas não se iluda, não vai ser fácil de publicar. Vai ter revisor que não vai gostar. Você tem que convencer o editor para ele se aliar a você.

\section{Ilan: Fechamento da entrevista.}

\section{Referências}

Abramovitz, M. (1986). Catching up, forging ahead, and falling behind. Journal of Economic History, 385-406.

Barney, J. B. (1991). Firm resources and sustained competitive advantage. Journal of Management, 17(1), 99-120.
Coase, R. H. (1937). The Nature of the Firm. Economica, 4(16), 386-405. https://doi.org/10.1111/j.1468-

0335.1937.tb00002.x

Coase, Ronald H. (1960). The Problem of Social Cost. Economic Analysis of the Law: Selected Readings, $1-13$. https://doi.org/10.1002/9780470752135.ch1

Parente, R., Melo, M., Andrews, D., Kumaraswamy, A., \& Vasconcelos, F. (2020). Public sector organizations and agricultural catch-up dilemma in emerging markets: The orchestrating role of Embrapa in Brazil. Journal of International Business Studies. https://doi.org/10.1057/s41267-020-00325-x

Parente, R., Rong, K., Geleilate, J.-M. G., \& Misati, E. (2019). Adapting and sustaining operations in weak institutional environments: A business ecosystem assessment of a Chinese MNE in Central Africa. Journal of International Business Studies, 50(2), 275291. https://doi.org/10.1057/s41267-018-0179-z

Peng, M. W., \& Pinkham, B. (2009). The Institution-Based View as a Third Leg for a Strategy Tripod. Academy of Management Perspectives, 23(3), 63-81.https://doi.org/10.5465/AMP.2009.43479264

Princeton. (2018). What is the GMAT? The Princeton Review. https://www.princetonreview.com/business/gmatinformation

Williamson, O. (1975). Markets and hierarchies, analysis and antitrust implications: a study in the economics of internal organization. Free Press.

\section{Sobre o autor}

Ronaldo Couto Parente - Florida International University, Miami, (Flórida). E-mail: ronaldo.parente@fgv.br Orcid id: https://orcid.org/0000-0001-5338-5088

Ilan Avrichir - Escola Superior de Propaganda e Marketing - ESPM, São Paulo, (Brasil). E-mail: iavrichir@espm.br Orcid id: https://orcid.org/0000-0001-8234-3872

\section{Como citar este artigo:}

Parente, R., \& Avrichir, I. (2021). Entrevista com o Professor Ronaldo Parente: O árduo caminho para publicações internacionais de alto impacto. Internext, 16(1), 12-18. doi: http://dx.doi.org/10.18568/internext.v16i1.638 